\title{
Geociências
}

\section{Rubi e Safiras de Minas Gerais, Brasil}

\author{
Antonio Liccardo \\ DEGEO, Universidade Federal de Ouro Preto - UFOP \\ E-mail: liccardo@ambienteimagem.com.br
}

Ester Figueiredo Oliveira

Centro de Desenvolvimento de Tecnologia Nuclear - CDTN

Hanna Jordt-Evangelista

DEGEO, Universidade Federal de Ouro Preto - UFOP

E-mail:hanna@degeo.ufop.br

\section{Resumo}

Rubis e safiras de quatro depósitos em Minas Gerais, denominados Sapucaia, Indaiá e Palmeiras, na região de Caratinga-Manhuaçu, e Malacacheta, mais ao norte, foram caracterizados em termos geológicos, gemológicos, químicos e espectroscópicos, com o objetivo de interpretar causas de cor, gênese, bem como analisar o potencial econômico dos depósitos. Resultados de análises químicas e espectroscopia UV-visível mostram que a provável causa da cor azul é transferência de cargas entre $\mathrm{Fe}^{2+} \mathrm{e} \mathrm{Ti}^{4+}$, enquanto $\mathrm{Cr}^{3+}$ causa tonalidades violeta e púrpura, efeito alexandrita e fluorescência. A ausência de Ce e La e o teor relativamente mais alto de Ga distinguem as amostras de Malacacheta das demais. Além de sugerir particularidades genéticas, a diferença em termos de elementos-traços, pode ser utilizada como indicador de proveniência das gemas. Inclusões de um polimorfo de $\mathrm{Al}_{2} \mathrm{SiO}_{5}$ e indícios de campo sugerem que o coríndon deve ter sido gerado por processos metamórficos regionais, o que expande as possibilidades para a descoberta de novas ocorrências de rubi e safiras nos terrenos de alto grau metamórfico do leste de Minas Gerais.

Palavras-chave: Coríndon, rubi, safira, Minas Gerais, elementos traços, gemologia.

\begin{abstract}
Rubies and sapphires from four deposits in Minas Gerais named Sapucaia, Indaia and Palmeiras, in the region of Caratinga-Manhuaçu, and Malacacheta, farther north, were characterized in terms of geology, gemology, chemistry and spectroscopy in order to interpret causes of color and genesis. The economical potential of the deposits was also analyzed. Chemical analyses and UV-visible spectroscopy reveal that the probable cause of the blue color is a charge transfer between $\mathrm{Fe}^{2+}$ e Ti $i^{4+}$, while $\mathrm{Cr}^{3+}$ causes violet and purplish tints, alexandrite effect and fluorescence. Absence of Ce and La and relatively higher Ga-contents distinguish the Malacacheta samples from the others. Besides suggesting genetic particularities, the difference in terms of trace elements might be used as a provenience indicator for the gems. Inclusions of an $\mathrm{Al}_{2} \mathrm{SiO}_{5}$ polimorph and field evidences suggest that the origin of corundum might be due to regional metamorphic processes, thus expanding the possibilities for the discovery of new occurrences of ruby and sapphires in the high grade metamorphic terrain in eastern Minas Gerais.
\end{abstract}

Keywords: Corundum, ruby, sapphire, Minas Gerais, trace-elements, gemology. 
Rubi e Safiras de Minas Gerais, Brasil

\section{Introdução}

Nos últimos anos, novas ocorrências de coríndon surgiram em Minas Gerais, conhecido produtor de gemas coradas e diamante. Os depósitos de Palmeiras, Indaiá, Sapucaia e Malacacheta produzem safiras azuis, com tons violeta ou púrpura e rubi de tamanhos pequenos, mas com boa intensidade de cor e transparência. Indaiá é um depósito já conhecido (Epstein et al. 1994; Liccardo, 1999) e que teve sua produção interrompida em 1996, mas que, esporadicamente, apresenta alguma produção por garimpeiros. Do mesmo modo que em Indaiá, Palmeiras e Sapucaia, descobertas recentes na mesma região, apresentam um bom potencial gemológico, com gemas de tonalidades variando do azul ao púrpura, às vezes com efeito alexandrita, eventualmente com presença de rubi (Liccardo e Jordt-Evangelista, 2001). O depósito de Malacacheta, conhecido há várias décadas como produtor de alexandrita, sempre produziu safiras azuis como subproduto nas minerações. Atualmente tais safiras estão sendo comercializadas como material lapidável e sendo tratadas termicamente em Bangkok. Esse artigo reporta características desses depósitos e suas gemas, assim como mais informações sobre as já conhecidas safiras de Indaiá.

\section{Histórico}

A presença de coríndon no Brasil tem sido mencionada há muito tempo em literatura(Hussak, 1916; Guimarães, 1934), sem que existisse, no entanto, uma produção de material com qualidade-gema. A primeira menção de safiras azuis com qualidade para lapidação foi em Coxim, Mato Grosso do Sul (Eppler, 1964). Nesses depósitos, a safira é encontrada como mineral satélite em cascalhos produtores de diamante e nunca houve produção constante, sendo que algumas pedras são esporadicamente comercializadas.

Em Malacacheta, pequenos cristais de safira azul e incolor/leitosa foram retirados juntamente com crisoberilo e alexandrita durante anos, desde a década de 80 , contudo com pouca produção comercial.
A descoberta dos depósitos de Indaiá no início da década de 90 foi a mais promissora até então, tendo sido descrita por Themelis (1994) como a primeira ocorrência comercial de coríndon no Brasil. Em 1999, iniciou-se uma pequena produção em Sapucaia, cerca de $25 \mathrm{~km}$ ao sul de Indaiá, com gemas muito semelhantes, inclusive com moderado efeito alexandrita (Liccardo \& Jordt-Evangelista, 2000). Em 2000, surgiram notícias sobre o depósito de Palmeiras, cerca de $60 \mathrm{~km}$ a sudeste de Sapucaia, com gemas semelhantes aos depósitos anteriores, mas com tons predominantemente mais avermelhados. A falta de tradição na exploração de rubi e safira, em meio a tantas outras gemas no Estado de Minas Gerais, faz com que os garimpeiros que atuam nos pegmatitos da região concentrem-se na extração de outras gemas, principalmente água-marinha e, em Malacacheta, alexandrita e crisoberilo.

\section{Localização e acessos}

Três dessas ocorrências situam-se no eixo Manhuaçu-Caratinga, cerca de $250 \mathrm{~km}$ a leste de Belo Horizonte (Figura
1). A ocorrência de Indaiá pertence ao município de Vargem Alegre, aproximadamente a $20 \mathrm{~km}$ a noroeste de Caratinga, a montante do Córrego São Gabriel. No município de Sapucaia, cerca de $25 \mathrm{~km}$ a sudoeste de Caratinga, nas cabeceiras do córrego Ferrugem, encontra-se a segunda ocorrência. O depósito de Palmeiras situa-se no município de Manhuaçu, no distrito de mesmo nome, $12 \mathrm{~km}$ a noroeste da cidade. Nessas ocorrências, o acesso, em parte, é feito por estradas de terra, que, na estação das chuvas (setembro a janeiro), tornam-se dificilmente transitáveis.

Os depósitos de Malacacheta situam-se às margens do córrego do Fogo e ribeirão Soturno, a aproxidamente $12 \mathrm{~km}$ a norte da cidade de Malacacheta. $\mathrm{O}$ acesso a essa região é um pouco melhor que os das anteriores, mesmo na estação de chuvas. Malacacheta está cerca de $270 \mathrm{~km}$ da região de Indaiá, Palmeiras e Sapucaia.

\section{Contexto geológico regional}

O coríndon da região de Manhuaçu-Caratinga se encontra em depósitos secundários sobre terrenos gnáissicos-

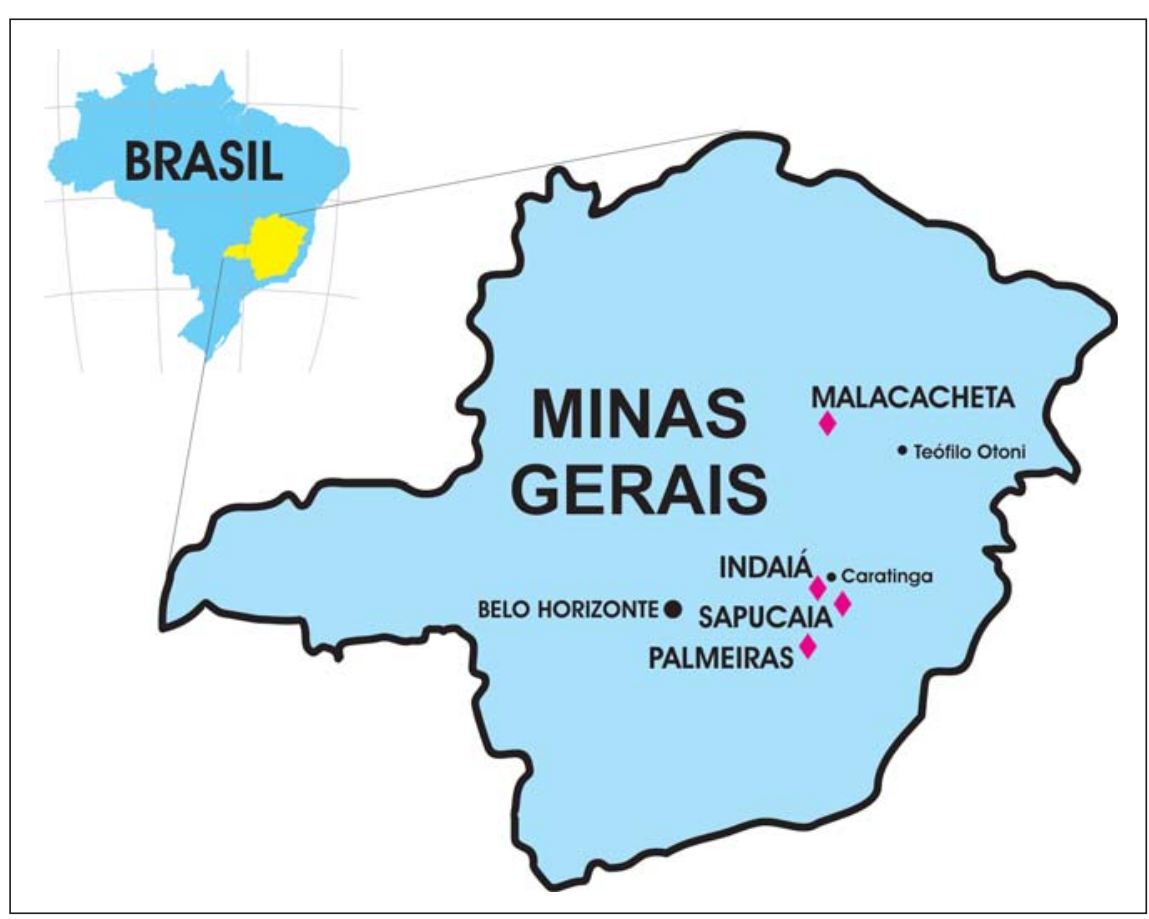

Figura 1 - Localização das ocorrências de coríndon estudadas. 
migmatíticos, com presença eventual de litotipos granulíticos e charnoquíticos, além de inúmeros corpos pegmatíticos que entrecortam todas as rochas (Figura 2). Os terrenos fazem parte do núcleo do Orógeno Neoproterozóico Araçuaí (Pedrosa-Soares \& Wiedemann-Leonardos, 2000).

Em Malacacheta, os depósitos também são colúvio-aluvionares encaixados em rochas metamórficas pré-cambrianas. Regionalmente, o contexto geológico mostra a existência de um batólito granítico intrudido em xistos peraluminosos das Formações Salinas e Capelinha e rochas metaultramáficas que cortam os xistos da Formação Capelinha (Figura 2). O corpo granítico, sem indícios de metamorfismo, foi datado em $537 \pm 8 \mathrm{Ma}(\mathrm{Ba}-$ sílio, 1999) e as rochas encaixantes são de idade proterozóica.

\section{Características dos depósitos}

Na faixa que compreende os depósitos de coríndon, ocorrem litologias pertencentes a terrenos metamórficos de médio até alto grau, como xistos, gnaisses, granulitos e charnoquitos. Esses terrenos são cortados por corpos pegmatíticos pouco diferenciados, por vezes mineralizados em água-marinha. $\mathrm{O}$ coríndon é sempre encontrado em depósitos sedimentares recentes, sem indícios da possível rocha que o originou.

Os depósitos podem abranger cinco tipos gerais: aluviões recentes, paleoaluviões de terraço suspenso, paleoaluviões de fundo de vale, colúvios e elúvios. A grande maioria dos depósitos de coríndon está associada a paleoaluviões plio-pleistocênicos, formados sob condições de fluxos torrenciais e retrabalhamento (Addad, 2001). Os depósitos ocupam atualmente as partes mais profundas dos preenchimentos sedimentares de vales, onde armadilhas de relevo condicionaram sua deposição, ou terraços aluvionares suspensos, relacionados ao desenvolvimento de paleo- superfícies. A alta densidade do coríndon faz com que esteja associado a pesados blocos de quartzo e fragmentos de encaixantes, nas porções mais inferiores.

Nesse contexto secundário, o retrabalhamento sedimentar fragmenta e "seleciona" os clastos e os concentra em níveis e pláceres. Do ponto de vista do seu aproveitamento gemológico, essa seleção fornece fragmentos com menor quantidade de defeitos de cristalização, de fraturas e inclusões, que correspondem a partes com maior resistência mecânica a impactos e abrasão. Isto significa que, a partir de uma população original de fragmentos, existe uma tendência segundo a qual, após o transporte por uma determinada distância dentro de um fluxo sedimentar, os clastos recuperados apresentam uma maior porcentagem de qualidade gema, pela eliminação de fragmentos mecanicamente mais frágeis.

\section{Métodos de extração}

Os depósitos de coríndon, usualmente inconsolidados, mostram uma relativa facilidade mecânica de explotação. Camadas de sedimentos cobrem os níveis mineralizados, geralmente cascalheiras aluvionares ou porções grosseiras de colúvios. O descapeamento não oferece maiores dificuldades técnicas, salvo quando se trata de aluviões recentes ou paleoaluviões posicionados sob leitos ativos de cursos de água, quando é necessário o bombeamento da água infiltrada ou o isolamento da porção a ser trabalhada. As gemas podem, então, ser separadas por processos que envolvem classificação granulométrica, lavagem e concentração-catação.

Em Indaiá, após o rush da extração, em meados de 90 (Epstein et al. 1994), os garimpos paralisaram os trabalhos e hoje a extração é realizada individualmente nos leitos dos rios. O mesmo acontece

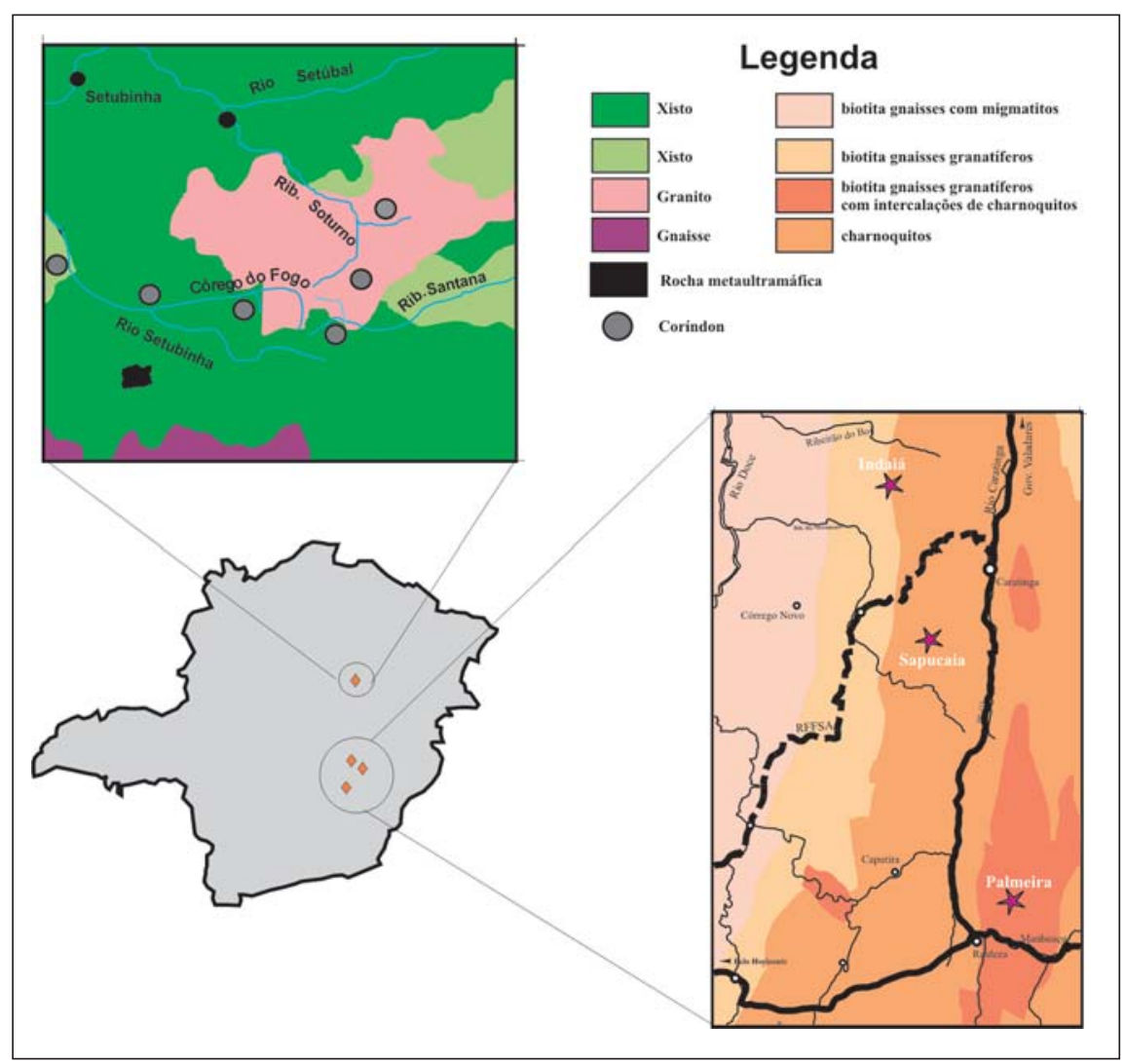

Figura 2 - Esboços geológicos das áreas de ocorrência de coríndon em Malacacheta (Basílio, 1999) e na região de Manhuaçu-Caratinga (simplificado de IGA/SECT, Projeto Radar Minas Gerais 1:500.000, 1978). 
em Sapucaia, que ao final da década era trabalhada com tratores e calhas para a concentração do material. $\mathrm{Na}$ área de Palmeiras, somente garimpos em aluvião estão produzindo, apesar de tentativas de mecanização. A extração organizada tem esbarrado em problemas ambientais e, por isso, está paralisada.

Em Malacacheta, as áreas de extração (cerca de $4 \times 4 m$ ) são escoradas com madeira para contenção de terra e a água é bombeada continuamente com motores movidos a diesel ou gás. Equipes de até cinco pessoas trabalham em cada área, retirando o material mineralizado e buscando, principalmente, a alexandrita, que ocorre associada.

\section{Amostras e análises}

Amostras de coríndon, juntamente com seus minerais satélites, foram coletadas com lavagem de cascalho e peneiramento. A quantidade de material em bruto permitiu análises destrutivas e algumas amostras coletadas puderam inclusive ser lapidadas. Em Palmeiras, foram obtidas 16 gemas facetadas e $18 \mathrm{ca}-$ bochões; em Sapucaia, 6 facetadas e 4 cabochões; em Malacacheta, 4 facetadas e, em Indaiá, 5 facetadas.

As amostras das quatro ocorrências foram submetidas a análises gemológicas tradicionais e, ainda, cinco exemplares de cada depósito foram moídos para análises químicas por INAA (Análise por Ativação Neutrônica Instrumental) e uma por ICP-OES (Plasma Indutivamente Acoplado com Espectrometria de Emissão Óptica), para complementação de alguns elementos. Além disso, foram realizadas análises em espectroscopia UV-Visível, ATD/ATG (Análises Termodiferencial e Termogravimétrica) e MEV/EDS (Microscopia Eletrônica de Varredura com Espectrometria de Energia Dispersa). As amostras submetidas à espectroscopia foram preparadas em secções cortadas perpendicularmente ao eixo c dos cristais. Os testes termodiferencial e termogravimétrico realizados em um mineral anidro (coríndon) resultam na identificação de fases hidratadas associadas a esse mineral, como a bohemita e o diásporo.

\section{Características e resultados}

\subsection{Malacacheta}

A safira de Malacacheta ocorre em cristais euédricos transparentes, no formato típico de barrilete e tamanho normalmente pequeno $(<1 \mathrm{~cm})$. A maior parte apresenta um marcante zonamento de cor, sendo incolor com um núcleo ou mancha de coloração azul intenso, boa transparência, tendendo a translúcida, principalmente na parte incolor. O pleocroísmo nas amostras azuis costuma ser moderado, de azul-escuro a azul-claro. Fotografias representativas de amostras de Malacacheta encontram-se nas Figuras 3 e 4 . Análises gemológicas convencionais resultaram num índice de refração variando de 1,759 a 1,764 para o raio extraordinário e 1,767 a 1,770 para o raio ordinário. A birrefringência média é de 0,009 (Tabela 1). Sob luz UV essas safiras mostram resposta moderada a fraca, de tons avermelhados para todas as amostras azuis, tanto em SW como em LW. Uma amostra incolor a levemente rosada apresentou reação muito forte ao UV de ondas longas (LW).

As inclusões sólidas identificadas em microscópio óptico e microscópio eletrônico de varredura foram ilmenita, ilmenita magnesiana e um polimorfo de $\mathrm{Al}_{2} \mathrm{SiO}_{5}$. O comportamento, na análise termogravimétrica, indica ausência de diásporo ou boehmita, comumente presentes em coríndon e causadores de perda de transparência.

As análises químicas resultaram, para as amostras de Malacacheta, na seguinte composição em elementos menores e traços: $\mathrm{Cr} 20$ a 58ppm, Fe 3582 a 4415ppm; Ga 180 a 192ppm; Ti 392ppm; Na 69-90ppm; Mn 13ppm; La 0 a 3ppm e V 18ppm (Tabela 2 - para o Ti, Mn e V somente uma análise). A presença desses elementos indica que, muito provavelmente, a coloração azul das safiras de Malacacheta tenha como causa uma transferência de cargas eletrônicas entre os íons $\mathrm{Fe}^{+2}$ e o $\mathrm{Ti}^{+4}$. Considerandose esses teores de Fe e Ti e as características ópticas da safira, é possível que um tratamento térmico sob condições adequadas possa redistribuir a coloração azul ou mesmo transformar a cor branca leitosa em azul profundo na maior parte do material produzido em Malacacheta. Os espectros UV-Visível mostraram picos intensos nas regiões de 485 e $585 \mathrm{~nm}$, possivelmente associados à presença de $\mathrm{Fe}^{3+}$ (Figura 6).

\subsection{Indaiá}

Safiras de colorações que variam de azul profundo ao violeta, quase púrpura (Figuras 3 e 4), são encontradas em depósitos coluvionares e aluvionares de Indaiá. Os cristais apresentam-se anédricos, geralmente de tamanho pequeno $(<1 \mathrm{~cm})$ e alguns mostram um moderado efeito alexandrita de azul para azul-púrpura e de púrpura para púrpura-violeta.

As análises gemológicas mostraram um pleocroísmo forte de azul para azul-violeta e de azul-claro para púrpura. Os índices de refração variam de 1,760 a 1762 para o raio extraordinário e 1,770 para o raio ordinário, com birrefringência variando de 0,008 a 0,010 . Sob luz UV de ondas longas ( $\mathrm{LW}$ ), as amostras apresentam fluorescência variável de moderada a forte com coloração avermelhada (Tabela 1).

As inclusões são constituídas de rutilo, ilmenita, zircão, moscovita, monazita (Figura 5), espinélio, biotita (Figura 5) e um dos polimorfos de $\mathrm{Al}_{2} \mathrm{SiO}_{5}$.

Análises químicas e espectroscópicas mostraram a presença de Fe, Ti e Cr como prováveis elementos causadores de cor nessas safiras. O efeito de mudança de cor (efeito alexandrita) e a forte fluorescência são associados à presença do íon $\mathrm{Cr}^{3+}$. Os elementos menores e traços quantificados foram: $\mathrm{Cr} 191$ a 390ppm, Fe 2626 a 3615ppm; Ga 60 a 93ppm; Ti 185ppm; Na 57-78ppm; Mn 13 ppm; La 19 a 81ppm; Ce 66 a 159ppm e V 44ppm (Tabela 2 - para o Ti, Mn e V somente uma análise). 

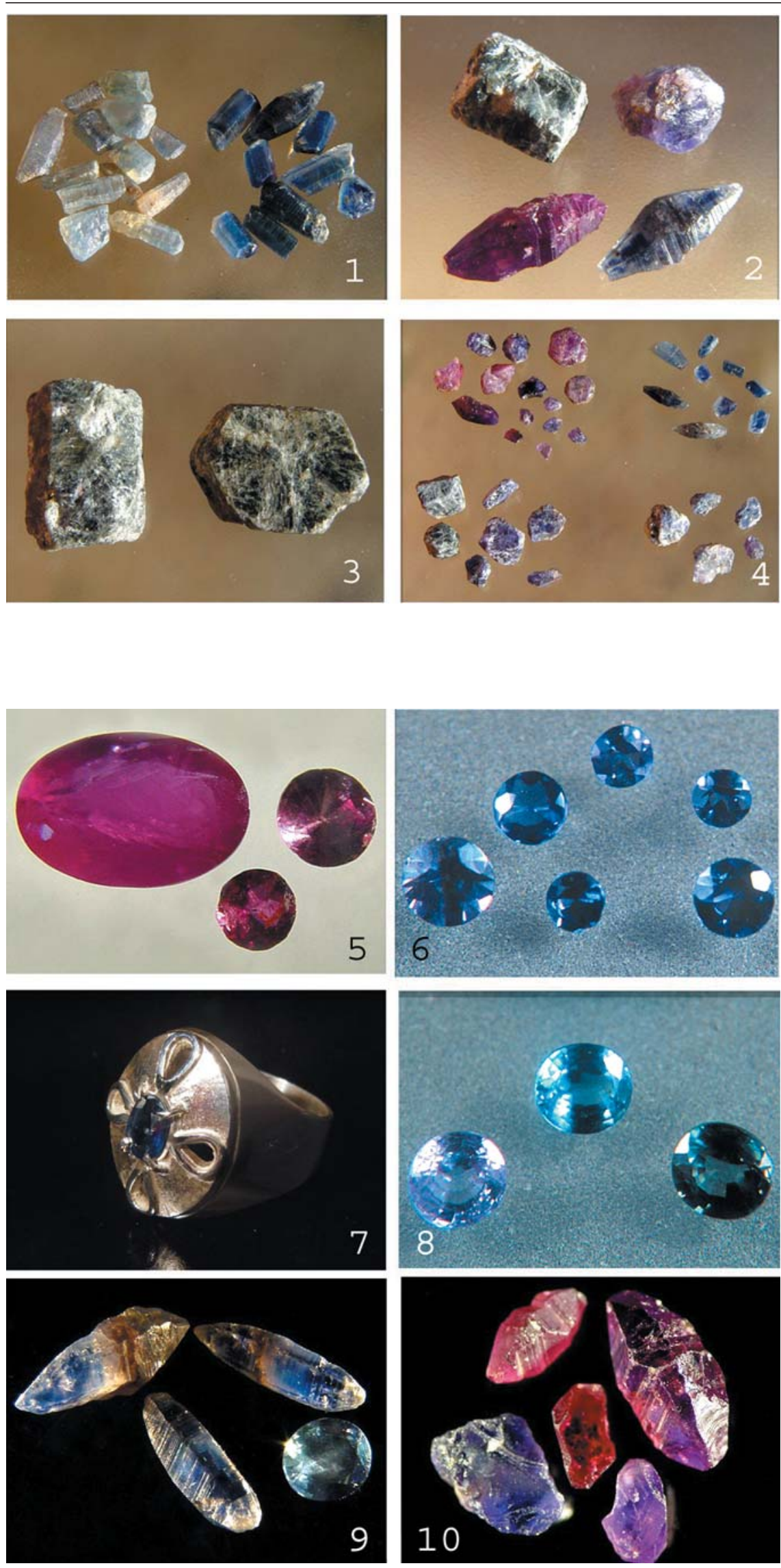

Figura 3 - Fotografias de amostras de coríndon de diversas ocorrências estudadas

1: Exemplares de safiras provenientes de Malacacheta. A coloração esbranquiçada e leitosa à esquerda apresenta o típico aspecto das safiras geuda, do Sri Lanka, que com tratamento térmico passa para os tons azuis à direita. Alguns fragmentos apresentam ambas colorações no mesmo cristal. Dimensões em torno de $1 \mathrm{~cm}$.

2: Exemplares característicos das ocorrências de Sapucaia, Indaiá (em cima), Palmeiras (rubi abaixo) e Malacacheta (safira em forma típica de barrilete). Os barriletes medem $1 \mathrm{~cm}$.

3: Entre o material retirado de Sapucaia, algumas safiras negras apresentam zonamento de cor radial, que lembram algumas safiras chamadas trapiche, recentemente descobertas na Tailândia. Esses exemplares medem cerca de $2 \mathrm{~cm}$.

4: Variação de cor e hábito do material produzido em Palmeiras (acima e à esquerda), Malacacheta (acima e à direita), Sapucaia (abaixo e à esquerda) e Indaiá (abaixo e à direita). Exemplares maiores medem cerca de $1 \mathrm{~cm}$.

Figura 4 - Fotografias de amostras de coríndon de qualidade gemológica de diversas ocorrências estudadas.

5: Exemplares de rubi de Palmeiras. A gema em lapidação oval pesa 1,3 quilates.

6: Amostras lapidadas de safira azul de Sapucaia. A gema maior pesa 0,3 quilates.

7: Anel em prata com safira azul proveniente de Indaiá $(0,8 \mathrm{ct})$.

8: Amostras de safira azul provenientes de Malacacheta, pesando entre 0,5 e 0,7 quilates.

9: Cristais euédricos de safira bicolor de Malacacheta. A gema lapidada é aproveitada da parte azul dos cristais. Os barriletes medem em torno de $1 \mathrm{~cm}$.

10: Variação de cor do material obtido em Palmeiras. O cristal maior mede $1 \mathrm{~cm}$. 
Rubi e Safiras de Minas Gerais, Brasil

Tabela 1 - Características gemológicas do coríndon das ocorrências estudadas.

\begin{tabular}{|c|c|c|c|c|}
\hline Propriedades & Malacacheta & Palmeiras & Indaiá & Sapucaia \\
\hline Cor $\left({ }^{*} 100\right)$ & $\begin{array}{c}\text { Azul-claro, azul- } \\
\text { médio, bicolor, incolor }\end{array}$ & $\begin{array}{l}\text { Vermelho, violeta, } \\
\text { rosa, azul }\end{array}$ & Azul, púrpura, violeta & Azul, violeta, preta \\
\hline $\begin{array}{l}\text { Transparência } \\
(100)\end{array}$ & Boa a translúcida & Boa a opaca & Boa a opaca & $\begin{array}{l}\text { Boa a opaca. Safira } \\
\text { preta sempre opaca }\end{array}$ \\
\hline $\begin{array}{l}\text { Efeitos ópticos } \\
\text { (30) }\end{array}$ & Não & $\begin{array}{l}\text { Efeito alexandrita, } \\
\text { seda e asterismo }\end{array}$ & Efeito alexandrita & $\begin{array}{l}\text { Ef. alexandrita, seda e } \\
\text { asterismo (safira preta) }\end{array}$ \\
\hline \multirow{2}{*}{$\begin{array}{l}\text { Índice de refração } \\
\text { (10) }\end{array}$} & $1,759-1,764(n e)$ & $1,761-1,763(n e)$ & $1,760-1,762(n e)$ & $1,759-1,762(n e)$ \\
\hline & $1,767-1,770(n w)$ & $1,769-1,771(n w)$ & $1,770-1,770(n w)$ & $1,768-1,770(n w)$ \\
\hline $\begin{array}{l}\text { Birrefringência } \\
\text { (10) }\end{array}$ & 0,009 & $0,008-0,010$ & $0,009-0,010$ & 0,009 \\
\hline $\begin{array}{l}\text { Peso específico } \\
\text { (10) }\end{array}$ & $3,99-4,01$ & $4,00-4,03$ & $4,02-4,07$ & $4,00-4,08$ \\
\hline Pleocroísmo (10) & $\begin{array}{l}\text { Moderado } \\
\text { Azul-escuro/claro }\end{array}$ & $\begin{array}{c}\text { Moderado a fraco } \\
\text { Verm/rosa - Viol/pur }\end{array}$ & $\begin{array}{l}\text { Moderado a Forte } \\
\text { Az/viol - Az/pur }\end{array}$ & $\begin{array}{c}\text { Moderado a forte } \\
\text { Az/vio - Viol esc/cla }\end{array}$ \\
\hline \multirow{3}{*}{$\begin{array}{l}\text { Fluorescência } \\
\text { (10) }\end{array}$} & SW - Fraca a mod. & SW - Fraca & SW - Mod. & $\begin{array}{l}\text { SW - Fraca a } \\
\text { mod.(violeta) }\end{array}$ \\
\hline & LW - Fraca a mod. & LW - Muito Forte & LW - Mod. & $\begin{array}{l}\text { LW - Mod. a forte } \\
\text { (violeta e púrpura) }\end{array}$ \\
\hline & $\begin{array}{c}\text { Muito forte averm. } \\
\text { para amostra incolor a } \\
\text { levemente rosa }\end{array}$ & Em tons vermelhos & Em tons vermelhos & \\
\hline Uv-visível (3) & $\begin{array}{c}\text { Picos em } 485 \mathrm{~nm} \text { e } \\
585 \mathrm{~nm}\end{array}$ & $\begin{array}{c}\text { Bandas entre } 370- \\
420 \mathrm{~nm} \text { e } 520-580 \mathrm{~nm}\end{array}$ & $\begin{array}{l}\text { Bandas entre } 370- \\
420 \mathrm{~nm} \text { e } 500-600 \mathrm{~nm}\end{array}$ & $\begin{array}{c}\text { Pico em 370nm e banda } \\
\text { em 520-580nm }\end{array}$ \\
\hline $\begin{array}{l}\text { Características } \\
\text { internas }(30)\end{array}$ & $\begin{array}{c}\text { Zonamento de cor } \\
\text { acentuado e aspecto } \\
\text { leitoso }\end{array}$ & $\begin{array}{l}\text { Geminação } \\
\text { polissintética e } \\
\text { fraturas }\end{array}$ & $\begin{array}{c}\text { Zonamento de cor e } \\
\text { fraturameto muito } \\
\text { intenso }\end{array}$ & $\begin{array}{c}\text { Zonamento de cor, } \\
\text { fraturas e presença de } \\
\text { diásporo }\end{array}$ \\
\hline Inclusões (10) & $\begin{array}{c}\text { Ilmenita, ilmenita } \\
\text { magnesiana, polimorfo } \\
\text { de } \mathrm{Al}_{2} \mathrm{SiO}_{5}\end{array}$ & $\begin{array}{c}\text { Zircão, rutilo, apatita, } \\
\text { ilmenita, hematita, } \\
\text { monazita e mica }\end{array}$ & $\begin{array}{c}\text { Rutilo, ilmenita, } \\
\text { zircão, moscovita, } \\
\text { monazita, espinélio, } \\
\text { biotita e polimorfo de } \\
\mathrm{Al}_{2} \mathrm{SiO}_{5}\end{array}$ & $\begin{array}{l}\text { Rutilo, ilmenita, mica e } \\
\text { polimorfo de } \mathrm{Al}_{2} \mathrm{SiO}_{5}\end{array}$ \\
\hline
\end{tabular}

(*) $\mathrm{N}^{0}$ de amostras para cada ocorrência. 

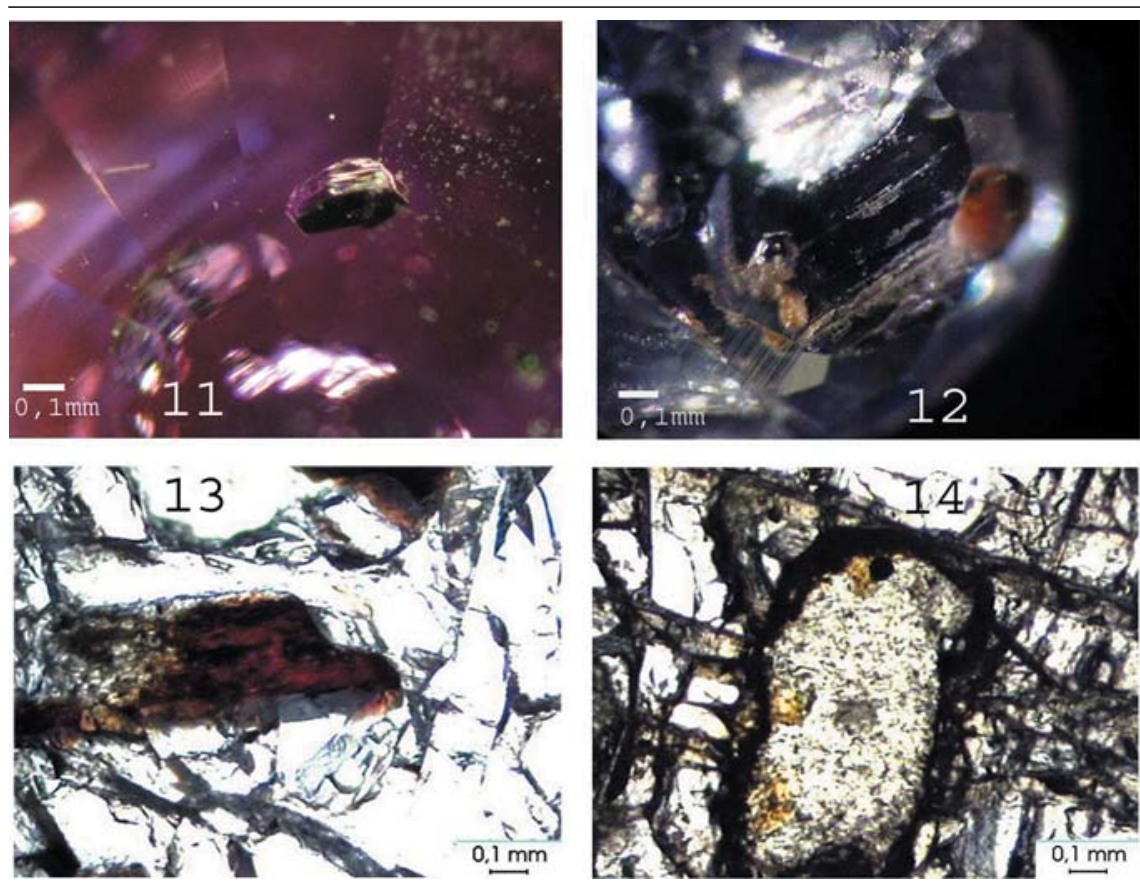

Figura 5 - Fotomicrografias de inclusões em amostras de coríndon de diversas localidades estudadas.

11: Inclusão cristalina em safira rosa proveniente de Palmeiras, possivelmente agregado de mica.

12: Inclusão de mica castanha em safira azul proveniente de Sapucaia.

13: Inclusão de lamela de biotita em safira azul de Indaiá.

14: Inclusão sólida em forma de grão arredondado, possivelmente monazita, em safira de Indaiá.

Em termos de cor e transparência, as safiras mostram um bom potencial para aproveitamento gemológico, o qual pode ser sensivelmente aumentado com tratamento térmico adequado. Themelis (1994) sugere que $80 \%$ do material produzido nessa localidade se prestaria ao tratamento por aquecimento, com base em testes que realizou em atmosfera oxidante e temperatura em torno de $1750^{\circ} \mathrm{C}$.

Os espectros referentes às amostras de Indaiá são muito semelhantes aos obtidos em Palmeiras e Sapucaia, mostrando uma banda de absorção entre 370 e $420 \mathrm{~nm}$, que, em safiras azuis do Sri Lanka, Mianmar, Vietnam e outras (Smith et al., 1995), é associada à presença de $\mathrm{Fe}^{3+}$. A faixa entre $500 \mathrm{e}$ $600 \mathrm{~nm}$, região indicativa do mecanismo $\mathrm{Fe}^{2+}-\mathrm{Ti}^{4+}$ e da presença de $\mathrm{Cr}^{3+}$, apresenta-se na forma de bandas largas e suaves (Figura 6).

\subsection{Sapucaia}

A safira de Sapucaia ocorre em cristais euédricos, subédricos e fragmentos irregulares, nas cores azul, púrpura, violeta e preta (Figuras 3 e 4). Apresenta-se em prismas hexagonais alongados e, muitas vezes, terminados em bipirâmide, sendo a superfície externa dos cristais normalmente lisa e freqüentemente recoberta por muscovita microcristalina. A maior parte dos cristais mostra dimensões em torno de $1 \mathrm{~cm}$, variando desde alguns milímetros até $8 \mathrm{~cm}$ de comprimento (o maior exemplar encontrado).

Os cristais exibem pronunciada partição basal e romboédrica nos planos de geminação polissintética. Em termos de diafaneidade, são opacos até transparentes e parte pode ser aproveitada como gema, apesar das abundantes fraturas. Nos exemplares translúcidos e transparentes, foi verificada uma distribuição irregular da cor, além de inclusões opa- cas. Como efeitos ópticos especiais, foram observados o efeito alexandrita (safiras azuis em luz natural tornam-se violetas sob iluminação incandescente), o efeito seda (brilho prateado sedoso) e, nas safiras pretas, ocorre, ainda, o asterismo com a formação de estrela de seis pontas.

As análises gemológicas mostraram pleocroísmo moderado a acentuado nas amostras azuis, púrpura e violeta. Os índices de refração variam de 1,759-1,762, para o raio extraordinário, e 1,768-1,770, para o raio ordinário, com birrefringência média de 0,009 (Tabela 1). Sob iluminação ultravioleta de ondas curtas (SW), as safiras mostraram uma reação fraca a moderada (violeta); em ondas longas, as amostras, nas cores violeta e púrpura, apresentaram reação de fluorescência muito forte (vermelha) e, nas outras cores, reação moderada (violeta).

As principais inclusões identificadas foram mica castanha (Figura 5), rutilo, ilmenita e um polimorfo de $\mathrm{Al}_{2} \mathrm{SiO}_{5}$, além da constatação de diásporo nos planos de geminação polissintética, muito semelhante ao material de Indaiá. As análises químicas mostraram os seguintes teores dos elementos menores e traços: Cr 54 a 1092ppm, Fe 4603 a 9312ppm; Ga 94 a 293ppm; Ti 361ppm; Na 58 a 169ppm; Mn 18 ppm; La 3 a 206ppm; Ce 21 a 300ppm e V 62ppm (Tabela 2 - para o $\mathrm{Ti}$, Mn e V somente uma análise).

Os estudos dessas safiras apontam boas possibilidades de aproveitamento gemológico, à semelhança da safira de Indaiá, principalmente em relação às de cor azul e violeta e com efeitos ópticos especiais. Possivelmente, esse aproveitamento poderá ser aumentado se essas safiras forem tratadas termicamente. Os espectros UV-Visível são semelhantes aos de Indaiá, com banda de absorção mais abrupta em torno de $370 \mathrm{~nm}$ e uma banda suave entre 520 e $580 \mathrm{~nm}$, provavelmente relacionadas ao mecanismo de cor $\mathrm{Fe}^{2+}-\mathrm{Ti}^{4+}$ (Figura 6). 
Rubi e Safiras de Minas Gerais, Brasil

Tabela 2 - Teores de elementos menores e traços em coríndon de Minas Gerais, analisados por INAA e ICP-OES* (em ppm).

\begin{tabular}{c|c|c|c|c|c|c|c|c|c}
\hline & $\mathbf{C r}$ & $\mathbf{F e}$ & $\mathbf{G a}$ & $\mathbf{N a}$ & $\mathbf{C e}$ & $\mathbf{L a}$ & ${ }^{*} \mathbf{T i}$ & ${ }^{*} \mathbf{M n}$ & ${ }^{*} \mathbf{V}$ \\
\hline Malacacheta & $20-58$ & $3582-4415$ & $180-192$ & $69-90$ & 0 & $0-3$ & 392 & 13 & 18 \\
\hline Palmeiras & $596-1293$ & $2022-3733$ & $71-114$ & $63-73$ & $98-368$ & $16-150$ & 172 & 9 & 57 \\
\hline Sapucaia & $54-1092$ & $4603-9312$ & $94-293$ & $58-169$ & $21-300$ & $3-206$ & 361 & 18 & 62 \\
\hline Indaiá & $191-390$ & $2626-3615$ & $60-93$ & $57-78$ & $66-159$ & $19-81$ & 185 & 13 & 44 \\
\hline
\end{tabular}

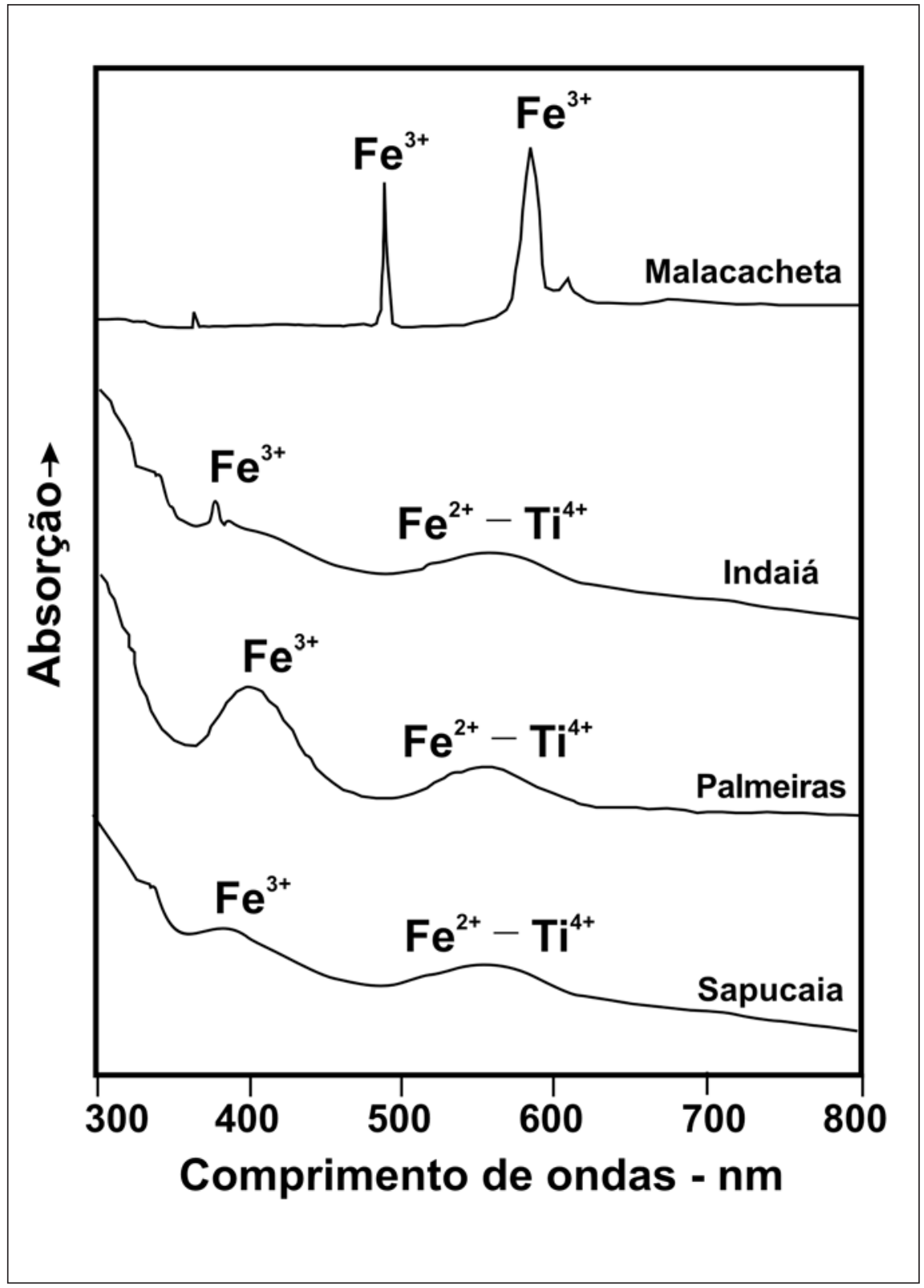

Figura 6 - Espectros de absorção no UV-Visível representativos para o coríndon das ocorrências estudadas.

\subsection{Palmeiras}

Os cristais encontrados em Palmeiras são euédricos, de coloração predominantemente avermelhada (rubi ou safira rosa), em menor escala também violeta ou púrpura e, raramente, azul, com hábito prismático alongado e em "barrilete", com tamanho variando de $0,5 \mathrm{a} 4 \mathrm{~cm}$ (Figuras 3 e 4). Alguns exemplares pequenos também mostraram o efeito alexandrita, semelhante a Indaiá e Sapucaia, mas o efeito óptico especial, que predomina nessas amostras, é o efeito seda e, esporadicamente, alguns rubis apresentam discreto asterismo. Uma parte dos cristais apresenta-se transparente, porém a maioria varia de opaca a translúcida.

Amostras de coloração vermelha e rosa apresentam pleocroísmo moderado para tons mais escuros e os cristais azuis e violeta possuem pleocroísmo fraco. Os índices de refração variam de 1,761 a 1,763 , para o raio extraordinário, e 1,769 a 1,771. para o raio ordinário. A variação da birrefringência é de 0,008 a 0,010. Sob luz ultravioleta de ondas curtas (SW), a reação foi muito fraca e, em ondas longas (LW), as amostras de cores vermelha e rosa mostraram fluorescência muito forte (Tabela 1).

Como inclusões sólidas ocorrem zircão, rutilo (arredondado e acicular), apatita, ilmenita, hematita, monazita e mica (Figura 5). Também, nessas amostras, o diásporo encontra-se nos planos de geminação polissintética.

Os teores dos elementos menores e traços são: Cr 596 a 1293ppm, Fe 2022 a 3733ppm; Ga 71 a 114ppm; Ti 172ppm; 
Antonio Liccardo et al.

Na 63 a 73ppm; Mn 9 ppm; La 16 a 150ppm; Ce 98 a 368ppm e V 57ppm (Tabela 2). A espectroscopia UV-Visível mostrou resultados muito semelhantes a Indaiá e Sapucaia, com banda de absorção de 370nm a 420nm e uma banda suave entre 520 e $580 \mathrm{~nm}$, provavelmente relacionadas à presença de $\mathrm{Fe}^{2+}-\mathrm{Ti}^{4+}$ nas amostras azuladas e $\mathrm{Cr}^{+3}$ nas amostras rosadas ou avermelhadas (Figura 6).

\section{Discussão}

A descoberta de diversas ocorrências de coríndon com qualidade gemológica em áreas relativamente próximas é um forte indicativo do potencial para a existência de outros depósitos e de aumento da produção de rubi e safiras no Brasil.

As análises químicas apontam as causas de cor azul como sendo o mecanismo de transferência de cargas entre $\mathrm{Fe}^{2+}$ e $\mathrm{Ti}^{4+}$ e a presença de $\mathrm{Cr}^{3+}$, possivelmente, influencia nas tonalidades violeta e púrpura, assim como pode estar associada ao efeito alexandrita e à forte fluorescência de algumas amostras, principalmente em Palmeiras e Indaiá. Nas amostras de coloração vermelha e com tonalidades rosa, os teores de Cr são sensivelmente mais altos, podendo ser vinculados como causa dessas cores. Os espectros em UV-Visível são coerentes com essas possibilidades.

A ausência de Ce e La e o teor relativamente mais alto de $\mathrm{Ga}$ distinguem o coríndon de Malacacheta do coríndon da região de Manhuaçu-Caratinga, o que pode sugerir diferenças genéticas e esse fato pode ser utilizado como indicador de proveniência.

Indícios de campo, como as rochas predominantes nas regiões, sugerem que a gênese do coríndon pode ser associada a processos metamórficos regionais, o que expande as possibilidades de existirem novas ocorrências em todo o leste de Minas Gerais, cujo contexto geológico é muito semelhante.

Os resultados analíticos e as características físicas descritas indicam que a aplicação de tratamento térmico adequado no coríndon estudado pode vir a melhorar significativamente a qualidade das gemas produzidas e viabilizar uma produção sistemática. Malacacheta, por apresentar produção constante, e Indaiá, pela qualidade de suas safiras, são as ocorrências com melhores possibilidades para a sistematização da extração.

\section{Referências bibliográfias}

ADDAD, J. E. Gemas de cascalho e aluviões In: CASTAÑEDA, C., ADDAD, J. E., LICCARDO, A. Gemas de Minas Gerais. Belo Horizonte: Ed. SBG, p.34-50. 2001.

BASÍLIO, M.S. A alexandrita de Malacacheta, Nordeste de Minas Gerais. Ouro Preto: Universidade Federal de Ouro Preto, 1999. 111 p. (Dissertação de Mestrado).

EPPLER, W.F. Sapphire from Rio Coxim, Mato Grosso. Journal of Gemmology. v. 9, p. 199-204, 1964
EPSTEIN, D.S., BRENNAN, W., CÉSARMENDES, J. The Indaiá Sapphire Deposists of Minas Gerais, Brazil. Gems \& Gemology, v.30, n. 1, p.24-32, 1994

GUIMARÃES, D. À margem do "Os satélites do diamante". Belo Horizonte: Serviço Geológico, Secretaria da Agricultura, 1934 $58 \mathrm{p} ., 15$ estampas. (Monografia 2).

HUSSAK, E. 1917. Os satélites do diamante. Publ. Do Serv. Geol. e Min. do Brasil, Rio de Janeiro. 1917

IGA/SECT - Instituto de Geociências Aplicadas da Secretaria de Estado de Ciências e Tecnologia, Minas Gerais. Mapa Geológico de Minas Gerais, Folha Belo Horizonte. Projeto Radar 1:500.000. 1978.

LICCARDO, A. Safiras de Indaiá, MG mineralogia, geologia e gemologia. Ouro Preto: Universidade Federal de |Ouro Preto, 1999. 126p. (Dissertação de Mestrado).

LICCARDO, A., JORDT-EVANGELISTA, H. Ocorrências de coríndon na porção leste de Minas Gerais. Geonomos. v. 8, n. 1, p.39-45, 2000

LICCARDO, A., JORDT-EVANGELISTA, H. Coríndon. In: CASTAÑEDA, C., ADDAD, J. E., LICCARDO, A. Gemas de Minas Gerais. Belo Horizonte: 2001. Ed. SBG, p. 234-259

PEDROSA-SOARES, A. C., WIEDEMANNLEONARDOS, C.M. Evolution of the Araçuaí Belt and its Connection to the Ribeira Belt, Eastern Brazil. In: CORDANI, U.G., MILANI, E. J., THOMAZ FILHO, A., CAMPOS, D.A. Tectonic Evolution of South America. Rio de Janeiro: SBG, 2000. p. 265-286.

SMITH, C.P., KAMMERLING R.C., KELLER A., PERETTI A., SCARRATT K.V., KHOA N.G., REPETTO, S. Sapphires from southern Vietnam. Gems \& Gemology, v. 31 , p. 168-186, 1995

THEMELIS, T. The heat treatment of ruby and sapphire. 1st ed. USA: Gemlab Inc, 1992. 236p.

Artigo recebido em 18/04/2005 e aprovado em 19/07/2005.

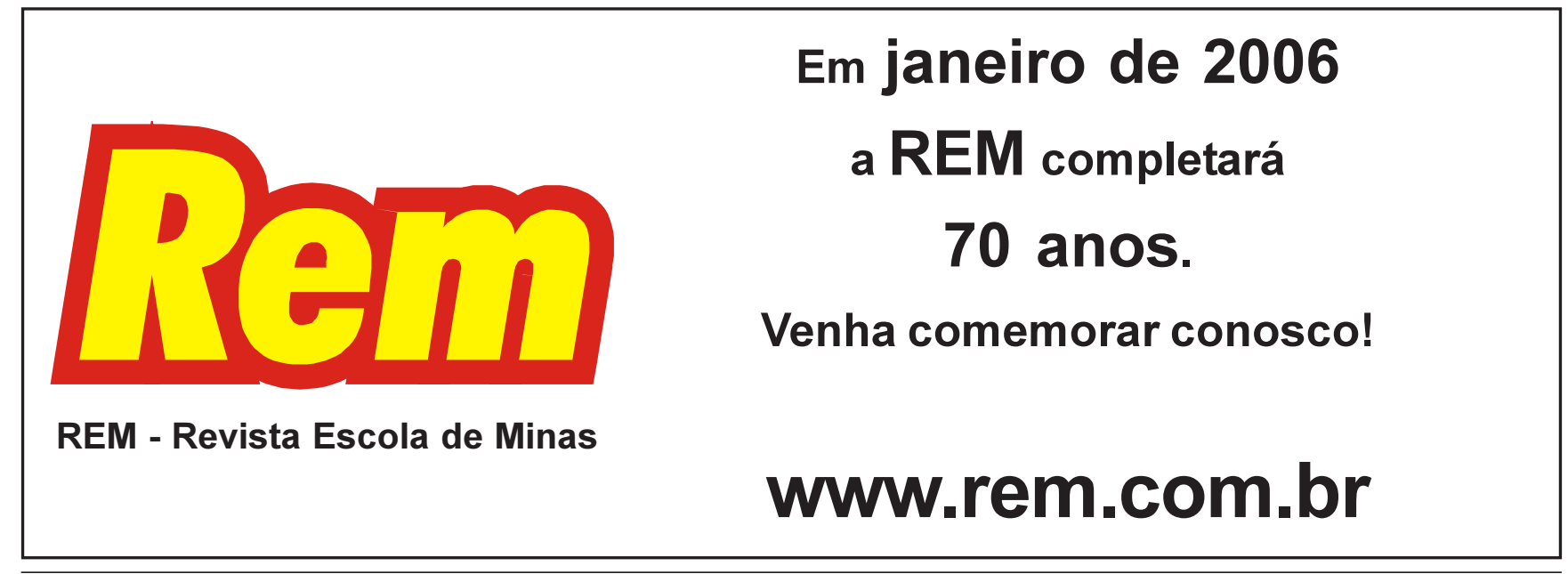

